\title{
RISK IN STREAM AND ROYALTY FINANCING OF INFRASTRUCTURE DEVELOPMENT
}

\author{
David G. Carmichael*, Craig G. Edmonson \\ School of Civil and Environmental Engineering, The University of New South Wales Sydney, Australia \\ (Received: December 2014 / Revised: December 2014 / Accepted: February 2015)
}

\begin{abstract}
Stream financing and royalty financing are relatively new ways of enabling the development of infrastructure in the resources sector and provide risk sharing between the parties involved (financing company and resource company), different to other financing methods. The paper explores the peculiarities of stream and royalty financing, and presents a straightforward method, via moments, of assessing the risk associated with the parties losing/gaining money. Analysis variables are characterized by expected values and variances, the latter being used to incorporate any uncertainty or variability. The method assists in understanding the sensitivity of the risk to changes in the underlying terms of the financing agreements and underlying variables. It permits the selection of preferred financing dependent on the risk attitudes of the parties. A case example study is given demonstrating the calculations involved, along with some commentary on non-financial risk issues.
\end{abstract}

Keywords: Infrastructure development, Risk, Second order moment, Stream financing, Royalty payments, Resources, Mining, Options

\section{INTRODUCTION}

In stream financing (also known as resource streaming or metal purchase agreements Careaga, 2012), the financing company (streaming company, stream financing company, underwriting financier, lender) provides an upfront loan for infrastructure development (or a series of loans, dependent on development milestones such as the obtaining of permits) to a resource company (the resource owner, mine owner, developer, borrower) for the right to purchase a percentage of the project's future production (Taplin and Deutscher, 2013). This percentage is generally fixed, but can change throughout the duration of the project.

The financing company purchases an agreed percentage of production, generally at the lesser of the market price and a fixed price as stated per the streaming agreement - this fixed price is generally substantially lower than the market price (Andersen and Honeyman, 2013). Upon the financing company selling product, the difference between the market price and the fixed price goes towards repaying the loan (Andersen and Honeyman, 2013). Stream financing is one of a number of ways for companies to share financial risk on a resources project. Streaming agreements are usually long term (10-15 years) in nature and often exist for the duration of the life of the resource extraction (Andersen and Honeyman, 2013). The resource company may be required to observe certain funding conditions, for example involving liquidity and the maintenance of the condition of the infrastructure.

*Corresponding author. E-mail: D.Carmichael@unsw.edu.au, Tel. (+61 2) 9385 6140, fax: (+61 2) 93856139 
Royalty agreements are an alternative way for resource companies wishing to raise capital to assist in the funding of project development and production (Franco-Nevada, n.d.). In royalty agreements, the resource company gives partial rights of a project to a financing company (royalty company, royalty financing company, lender) in return for an upfront payment. The financing company has the right to a fixed percent of the profit or revenue over the life of the resource extraction (Franco-Nevada, n.d.).

A financing company might maintain a portfolio of both 'streams' and 'royalties'

The resources industry is traditionally regarded as being highly volatile. Stream and royalty financing are methods of financing utilized in the resources industries as a way of dealing with financial risks. Small- to medium-sized resource companies generally lack sufficient capital to progress prospective projects from the development phase to the production phase. Stream financing and royalty payments allow this to happen, and are attractive due to the fact that they are non-dilutive to the resource company shareholders, and safer than debt financing.

Current industry analysis practice is to carry out the risk calculations deterministically. This may be supplemented with sensitivity-style analyses, but still the analysis remains deterministic and hence unable to value risk or assess option hedging in any rational way. The deterministic analysis includes present worth (PW) (equivalently, net present value, NPV), internal rate of return (IRR) and payback period (PBP) analyses using a discount rate that attempts to incorporate uncertainty (Careaga, 2012). Besides the questionable usage of discount rates, criticism of this practice derives from the inability to judge the degree to which an investment is viable, that is, it is unable to differentiate grades of separation from some viability benchmark - it is unable to establish the likelihoods of occurrence associated with the increments adopted in the sensitivity analysis. It is unable to establish true investment risk. It is also vulnerable to assumptions on the analysis variables, in that it does not properly account for potential variability or uncertainty in the cash flows, interest rate or lifespan. Some analysts may undertake a Monte Carlo simulation, but its numerical base prevents a deep understanding of the influence of the underlying variables. The approach below incorporates uncertainty as well as providing insight; it is a straightforward extension of deterministic present worth analysis, but allows a rational treatment of risk.

The preferred method of analysis adopted in this paper is that of a second order moment analysis where variables are characterized by their expected values and variances (Benjamin and Cornell, 1970; Ang and Tang, 1975). The variance terms reflect any uncertainty in the variables. The method is intuitively straightforward. No assumptions are required on the probability distributions of the underlying variables; the only assumption is that the resulting present worth follows a user-preferred distribution. The method assists in understanding the sensitivity of risk to changes in the underlying terms of the financing agreements and underlying variables. It permits the selection of a preferred financing arrangement dependent on the risk attitudes of the financing company and the resource company.

The paper first gives the underlying second order moment framework, leading to the establishment of risk. A case example study in the resources sector shows the cash flows of typical streaming and royalty agreements, and the financial risks for both the financing company and the resource company. Some calculations are performed to indicate typical results for different agreements.

In the case example study, the cash flows are uncertain because of uncertain resource prices and uncertain production. The expected values and variances of the cash flows are obtained from the expected values and variances of resource prices and production, which in turn are obtained from range and likelihood estimates. The present worth follows from 
knowing the cash flows, and risk knowledge follows from knowing the present worth; in particular the probability that the present worth is negative, $\mathrm{P}[\mathrm{PW}<0]$, is of interest in risk considerations. The analysis also gives insight into steam financing and royalty payments from the financing company and the resource company viewpoints, the allocation of risk between these two parties, and what needs to be done to mitigate the financial risks or optimize the risk allocation. Financial risk is seen to be dependent on reserves, resource price, currency exchange rate and production. Other risk occurs in technical, environment, safety and legislation areas.

The paper will be on interest to professionals concerned with establishing the financial risk in their projects.

\section{FINANCIAL ANALYSIS}

The financial analysis essentials presented here are general, allowing adaptation to the case example study covered later.

\section{Cash Flows}

Consider a general investment, with possible cash flows extending over the life, $\mathrm{n}$, of the investment. Let the net cash flow at each time period, $\mathrm{i}=0,1,2, \ldots, \mathrm{n}$, be the result of a number of cash flow components (random variables), $\mathrm{k}=1,2, \ldots, \mathrm{m}$. The cash flow components can be both revenue and cost related. There may be correlation between the cash flow components at the same period.

The net cash flow $\mathrm{X}_{\mathrm{i}}$ in any period can be expressed as,

$$
\mathrm{X}_{\mathrm{i}}=\mathrm{Y}_{\mathrm{i} 1}+\mathrm{Y}_{\mathrm{i} 2}+\ldots+\mathrm{Y}_{\mathrm{im}}
$$

where $Y_{i k}, i=0,1,2, \ldots, n ; k=1,2, \ldots, m$, is the cash flow in period $i$ of component $k$, with expected value $\mathrm{E}\left[\mathrm{Y}_{\mathrm{ik}}\right]$ and variance $\operatorname{Var}\left[\mathrm{Y}_{\mathrm{ik}}\right]$.

The expected value and variance of $\mathrm{X}_{\mathrm{i}}$ become,

$$
\begin{aligned}
& \mathrm{E}\left[\mathrm{X}_{\mathrm{i}}\right]=\sum_{\mathrm{k}=1}^{\mathrm{m}} \mathrm{E}\left[\mathrm{Y}_{\mathrm{ik}}\right] \\
& \operatorname{Var}\left[\mathrm{X}_{\mathrm{i}}\right]=\sum_{\mathrm{k}=1}^{\mathrm{m}} \operatorname{Var}\left[\mathrm{Y}_{\mathrm{ik}}\right]+2 \sum_{\mathrm{k}=1}^{\mathrm{m}-1} \sum_{\ell=\mathrm{k}+1}^{\mathrm{m}} \operatorname{Cov}\left[\mathrm{Y}_{\mathrm{ik}}, \mathrm{Y}_{\mathrm{i} \ell}\right]
\end{aligned}
$$

where $\operatorname{Cov}[$ ] is covariance. Alternatively, the variance expression can be written in terms of the component correlation coefficients, $\rho_{\mathrm{k} \ell}$, between $\mathrm{Y}_{\mathrm{ik}}$ and $Y_{i \ell}, k, \ell=1,2, \ldots, m$,

$$
\left.\left.\operatorname{Var}\left[\mathrm{X}_{\mathrm{i}}\right]=\sum_{\mathrm{k}=1}^{\mathrm{m}} \operatorname{Var}\left[\mathrm{Y}_{\mathrm{ik}}\right]+2 \sum_{\mathrm{k}=1}^{\mathrm{m}-1} \sum_{\ell=\mathrm{k}+1}^{\mathrm{m}} \rho_{\mathrm{k} \ell} \sqrt{\operatorname{Var}\left[\mathrm{Y}_{\mathrm{ik}}\right.}\right] \sqrt{\operatorname{Var}\left[\mathrm{Y}_{\mathrm{i} \ell}\right.}\right]
$$

\section{Present Worth}

From the cash flows, the present worth may be characterised. The present worth, PW, is the sum of the discounted $\mathrm{X}_{\mathrm{i}}, \mathrm{i}=0,1,2, \ldots, \mathrm{n}$, according to,

$$
\mathrm{PW}=\sum_{\mathrm{i}=0}^{\mathrm{n}}\left[\frac{\mathrm{X}_{\mathrm{i}}}{(1+\mathrm{r})^{\mathrm{i}}}\right]
$$

where $r$ is the interest rate. The expected value and variance of the present worth become, 


$$
\begin{aligned}
& E[P W]=\sum_{i=0}^{n} \frac{E\left[X_{i}\right]}{(1+r)^{i}} \\
& \operatorname{Var}[P W]=\sum_{i=0}^{n} \frac{\operatorname{Var}\left[X_{i}\right]}{(1+r)^{2 i}}+2 \sum_{i=0}^{n-1} \sum_{j=i+1}^{n} \frac{\operatorname{Cov}\left[X_{i}, X_{j}\right]}{(1+r)^{i+j}}
\end{aligned}
$$

Alternatively, the variance expression can be written in terms of the intertemporal correlation coefficients between $X_{i}$ and $X_{j}$, namely $\rho_{i j}$, rather than the covariance of $X_{i}$ and $X_{j}$,

$$
\operatorname{Var}[P W]=\sum_{i=0}^{n} \frac{\operatorname{Var}\left[X_{i}\right]}{(1+r)^{2 i}}+2 \sum_{i=0}^{n-1} \sum_{j=i+1}^{n} \frac{\rho_{i j} \sqrt{\operatorname{Var}\left[X_{i}\right]} \sqrt{\operatorname{Var}\left[X_{j}\right]}}{(1+r)^{i+j}}
$$

This simplifies for independent and perfectly correlated cash flows $\mathrm{X}_{\mathrm{i}}$.

\section{Present Worth Distribution}

Given that the present worth is obtained from additive components, namely the cash flows, then the central limit theorem gives that a reasonable probability distribution for present worth is a normal distribution. This view is supported by a number of authors, for example Hillier (1963) and Tung (1992). The normal distribution is described in terms of two parameters, a mean $\mu$, and standard deviation, $\sigma$, which can be found on knowing E[PW] and $\operatorname{Var}[\mathrm{PW}]$. Having $\mu$ and $\sigma$ completely describes the shape of the normal distribution for PW.

However, it is remarked that the user can adopt any other probability distribution considered suitable.

\section{Internal Rate of Return, Payback Period}

Internal rate of return, $\mathrm{P}[\mathrm{IRR}<\mathrm{r}]=\mathrm{P}[\mathrm{PW}<0 \mid \mathrm{r}]$, and payback period, $\mathrm{P}[\mathrm{PBP}>$ nominated $\mathrm{t}]=\mathrm{P}[\mathrm{PW}<0 \mid$ nominated $\mathrm{t}]$, follow from knowing the present worth $($ Carmichael, 2011, 2014).

\section{Option Value}

Options may be used as a hedging tool to cover against large fluctuations in the underlying prices and production. An option involves a right but not an obligation to do something in the future. Where the agreement between the financing company and the resource company incorporates an option to change something (for example the type of financing, or stream or royalty percentage rates) in the future, the option value may be calculated according to (Carmichael et al., 2011; Carmichael, 2014),

$$
\mathrm{OV}=\Phi \times \text { Mean of PW upside }
$$

Here, $\Phi=\mathrm{P}[\mathrm{PW}>0]$, the $\mathrm{PW}$ upside is the area of the PW distribution to the right of the origin $(\mathrm{PW}>0)$. OV applies to any type of option.

\section{STREAM FINANCING}

\subsection{Outline}

Stream financing is a relatively new method of financing, and consequently there is a shortage of historical information available to prospective users, particularly on risks (Careaga, 2012). The first application appears to have been in 2004 with an agreement to acquire mined silver (Silver Wheaton, n.d.). Stream financing appears to be gaining 
popularity and growing (Andersen and Honeyman, 2013; Careaga, 2012). It could be anticipated to be most attractive to small- and medium-size resource companies (Breen, 2013). Large companies are more likely to have sufficient capital to fund the exploration and expansion of new and existing reserves. Stream financing finds a home predominantly in countries with low political risk (Careaga, 2012).

\subsection{Nature of a Streaming Agreement}

In a streaming agreement, a financing company makes an upfront payment to a resource company for the right to purchase a percentage of the future production (Taplin and Deutscher, 2013). The upfront payment may be in one or several instalments, based on milestones, for example related to construction or obtaining permits (Andersen and Honeyman, 2013). Production can involve more than one resource type (Franco-Nevada, n.d.).

The financing company continues to make on-going payments for product delivered under the streaming agreement, generally for the life of the resource extraction (Andersen and Honeyman, 2013). The ongoing payments for product are based on the lesser of a fixed price (as stated in the streaming agreement) and the current market price. In the event that the market price is higher than the fixed price, the difference is credited against the initial payment. The resource company may be obligated to return any of the un-credited initial payment at the end of the agreement (Andersen and Honeyman, 2013). This helps to align the interests of both companies. The resource company sacrifices future profits in order to repay the borrowed capital (Careaga, 2012).

Even after the initial payment has been reduced to zero, the financing company may still continue to purchase product at the lesser of the fixed price and the market price. There may be an increase in the fixed price after the initial payment has been repaid (Andersen and Honeyman, 2013).

The cash amount generated by the stream is dependent on the market price of the product and production. An increase in the market price of the product will be favourable for both the financing and resource companies. Similarly, a decrease in the market price of the product will result in a decrease in revenue for both parties (Careaga, 2012).

\subsection{Characteristics}

\subsubsection{Resource Company}

For resource companies, stream financing allows a reserve to be brought from the development stage into production, or assists in the expansion of existing projects (Careaga, 2012). Reserves can be developed on a location-by-location basis, or multiple reserves can be developed, allowing the creation of a portfolio of projects (Careaga, 2012), which spread any risks (Andersen and Honeyman, 2013).

It is non-dilutive to shareholders because it avoids equity financing, allowing the existing shareholders of the resource company to maintain the same levels of ownership, rather than introducing new shareholders (Lewis et al., 2013; Careaga, 2012). Earnings per share will be higher (Careaga, 2012) relative to equity-based financing. Retaining ownership allows the resource company to operate more freely, creating further opportunities in the future for growth and acquisitions (Lewis et al., 2013).

The resource company takes full responsibility for the efficiency of production; any increases in costs affect its profits (Andersen and Honeyman, 2013); the financing company does not get involved with the operation and associated risks. 


\subsubsection{Financing Company}

For financing companies, stream financing is regarded as safer than debt financing in the presence of fluctuating resource prices (Careaga, 2012). The financing company has a potential upside should prices for the product increase, but does not carry the downside risk associated with extraction or operation (Careaga, 2012; Andersen and Honeyman, 2013). However, it does carry the risk associated with the resource company defaulting on its loan. Although the financing company is not able to influence production (and events that affect production - industrial relations, environmental issues, hazards and related issues), it is in the interests of the resource company to have efficient production (Kalt, 2010).

\subsubsection{Both Resource and Financing Companies}

Both the financing company and the resource company are disadvantaged if the price for the product decreases. This increases the time that the resource company takes to pay back the loan, and the revenue for both the financing and resource companies falls (Careaga, 2012; Lewis et al., 2013).

Each streaming agreement is customised to the parties, with a view to managing the risks to both parties, whilst allowing for the possible inclusion of options for either party to modify an agreement (Kalt, 2010; Careaga, 2012; Andersen and Honeyman, 2013).

Both parties are exposed to errors in estimates of reserves, grade and recovery, price volatility of the product, and currency movements (Careaga, 2012; Sandstorm Gold, 2013). Other site-related risks are also present. For the resource company, these include that associated with non-efficient production resulting from poor industrial relations, exploration deficiencies, weather events, environmental matters and legislation, accidents and safety legislation, explosions and cave-ins and equipment failure (Sandstorm Gold, 2013). Cost increases are borne by the resource company. For the financing company, there may be limited opportunities to be compensated for inefficient production or a halt in production, leading to reduced or no revenue and profit (Sandstorm Gold, 2013). The associated risk is reduced through the financing company purchasing the product at a fixed price.

\subsection{Cash Flows}

There are both cash outflows and cash inflows for both the resource company and the financing company, over the life of any project (Table 1). Forecast revenue (cash inflow) for both parties depends on estimates of prices for the product and annual production.

Table 1. Cash flows for stream financing parties.

Resource company

\begin{tabular}{lll}
\hline Period, $\mathrm{i}$ & Cash inflow & Cash outflow \\
\hline 0 & - & $\begin{array}{l}\text { Initial loans provided to the } \\
\text { resource company. }\end{array}$ \\
$1,2, \ldots, \mathrm{n}$ & - & $\begin{array}{l}\text { Sale of product to the financing } \\
\text { company. }\end{array}$ \\
& - & Sale of product to other buyers. \\
\end{tabular}

Financing company

\begin{tabular}{lll}
\hline Period, $\mathrm{i}$ & Cash inflow & Cash outflow \\
\hline 0 & & - Initial loans provided to the \\
& & resource company. \\
$1,2, \ldots, \mathrm{n}$ & - Revenue from product sales. & - Product purchases. \\
\hline
\end{tabular}




\section{ROYALTY AGREEMENTS}

Two possible types of royalty agreements are those based on revenue, and based on profit (Franco-Nevada, n.d.). Careaga (2012) gives that the first royalty agreement occurred in 1986, written in terms of a percentage net profit interest of a gold mine's production.

\subsection{Revenue-based Royalty Agreement}

A revenue-based royalty agreement focuses on the value of the production or the net revenue received by the resource company (after operational costs have been taken out). In return for providing an initial payment to the resource company, the financing company is entitled to a fixed percentage of the revenue generated from the project, generally for the life of the resource extraction (Franco-Nevada, n.d.).

There are generally some deductions defined in the royalty agreement, for example relating to transportation, insurance, smelting and refining costs (Franco-Nevada, n.d.).

\subsection{Profit-based Royalty Agreement}

A net profit interest agreement focuses on the profit realised after deducting costs related to production, as laid out in the royalty agreement (Careaga, 2012; Franco-Nevada, n.d.). In return for providing an initial payment to the resource company, the financing company receives payments calculated as a percentage of net profit.

Increases in costs of production, the sole responsibility of the resource company, will have an effect on the net profit and royalties payable (Franco-Nevada, n.d.). Profit-based agreements are said to be the most popular type of royalty agreement. They incorporate upside and downside risk resulting from changes in the prices for the product, while limiting financial exposure for the resource company (Careaga, 2012; Callinan, n.d.).

\subsection{Cash Flows}

There are both cash outflows and cash inflows for both the resource company and the financing company, over the life of any project (Table 2). Forecast revenue (cash inflow) for both parties depends on estimates of prices for the product and annual production.

Table 2. Cash flows for royalty agreement parties.

Resource company

\begin{tabular}{lll}
\hline Period, $\mathrm{i}$ & Cash inflow & Cash outflow \\
\hline 0 & - $\begin{array}{l}\text { Initial loans provided to the } \\
\text { resource company. }\end{array}$ & - (Possible) initial capital outlay. \\
$1,2, \ldots, \mathrm{n}$ & - Sale of product to buyers. & - Royalty payments. \\
& & - Costs associated with production. \\
\hline
\end{tabular}

Financing company

\begin{tabular}{lll}
\hline Period, $\mathrm{i}$ & Cash inflow & Cash outflow \\
\hline 0 & & - $\begin{array}{l}\text { Initial loans provided to the } \\
\text { resource company. }\end{array}$ \\
$1,2, \ldots, \mathrm{n}$ & - Royalty payments. & \\
\hline
\end{tabular}

\section{ANALYSIS VARIABLES}

The financial risk analyses for both stream financing and royalty agreements, share the same elements. In both, cash flows are random variables. They contain uncertainty because of underlying uncertainty in:

- Production (itself dependent on uncertain reserves, grade and recovery).

- Prices for the product. 
- Project lifespan.

- Sales.

The cash flows, in a second order moment analysis, are characterised by their expected values and variances. (One of many possible ways of getting these is via first subjectively estimating optimistic, most likely and pessimistic values as described below.) The cash flows are discounted to give an expected value and variance of the present worth. From the distribution of the present worth, internal rate of return, payback period, risk and an option value may be obtained.

Both the resource company and the financing company need to perform risk analyses, but each from their own perspective. The resource company needs to examine each potential agreement on offer (including the contractual stream/royalty rate) and compare with other possible ways of financing. The financing company also needs to do a similar exercise in order to establish the project's rate of return and show that it is compatible with the company's required rate of return for investments.

\subsection{Prices for The Product}

Prices for resources are volatile. Prices depend on the global supply and demand for the resource, and are beyond the influence of the financing and resource companies. Demand depends on industry activity. For example, iron ore is used in manufacturing and construction, while gold ore is commonly used in jewellery, electronics and computers. Other factors affecting prices are the activities of various central banks, interest rates, currency exchange rates, inflation or deflation, fluctuations in the value of the American dollar and foreign currencies, and the political and economic conditions of major resource countries throughout the world (Sandstorm Gold, 2013).

Over recent years, there has been considerable volatility in the price of ores. For example, some ores and their approximate ranges are: iron ore, $\$ 100$ - $\$ 200$ per tonne; gold, $\$ 1150$ - \$1800 per ounce; and silver, \$20 - \$35 per ounce. Based on historical data together with some forecast of future events, it is possible to estimate optimistic, most likely and pessimistic values for prices; from these, expected values and variances of prices can be obtained.

If the prevailing market price for the product is at or below the price at which the financing company purchases it (as per the streaming agreement), the financing company will not generate a profit. Similarly, the resource company will need the market price to be higher than the cost of production, in order to generate a profit.

In co-product projects, under streaming agreements, resource and financing companies can reduce their exposure through a diversified income stream. Increases in the price of co-products can offset some losses incurred through a decrease in the price of a main product.

\subsection{Reserves}

Estimates by geologists of annual production and lifespans of projects are not precise, being based on sampling and geological interpretation. Actual product recovered may differ from reserve estimates. Accordingly, reserve estimates are revised as production progresses, in order to reduce the associated uncertainty. Market fluctuations in prices for the product and increased production costs can also affect the recovery rate, and may result in certain reserves becoming uneconomical (Sandstorm Gold, 2013).

\subsection{Production}

Future cash flow estimates depend on production estimates, themselves based on exploration results. Production depends on the grade and the recovery. Grade refers to the 
concentration of the desired product in its natural state. Recovery refers to the amount of product that is successfully extracted. Recovery is dependent on the geology surrounding the product.

Production is a function of grade, recovery and volume processed. Annual production estimates may range, for example, plus/minus ten percent.

\section{RISK}

Risk is a combination of probability and exposure (Carmichael, 2004, 2013). Generally, risk associated with financial exposure is the simpler to evaluate, compared with risk associated with intangibles. And so, most people's attention tends to centre on financial risk.

\subsection{Financial Risk}

With financial risk, the exposure is that of losing money. The probabilistic analysis presented in this paper, for each party, leads to an expected value, E[PW], and variance, $\operatorname{Var}[\mathrm{PW}]$, of the present worth, to which a distribution can be fitted. Consequently, it is possible to calculate the probability that the present worth is less than zero, $\mathrm{P}[\mathrm{PW}<0]$, the probability of losing money, $\mathrm{P}[\mathrm{IRR}<\mathrm{r}]$ and $\mathrm{P}[\mathrm{PBP}>$ nominated $\mathrm{t}]$.

\subsection{Financing Company Risks}

Only exposures related to the relationship between the financing and resource companies are raised here. Third party and more general business issues, such as taxation, access to favourable debt and equity finance and competitive streaming opportunities, and the resource company's obtaining of permits and licences, are not discussed.

\section{Operations}

The financing company has no influence over operations. The financing company may not be entitled to compensation if production targets are not realised, the project is shut down or operation is discontinued on a temporary basis. And there may be a difference between when production actually commences (if at all) and the anticipated commencement date. The termination of a project may result in a substantial loss for the financing company (Sandstorm Gold, 2013). The financing company is not able to purchase product as per any agreement if no production is actually occurring.

The resource company may choose to suspend or discontinue operations due to, for example, economic conditions, lack of capital, floods, fire, weather, mechanical malfunctions, community or social related issues, and the failure to receive permits or having existing permits revoked. These issues can be quite prevalent in the resources industry (Sandstorm Gold, 2013).

\section{Conflicting interests}

The resource company may have business interests, or take actions which are inconsistent with that of the financing company. The resource company may also be unwilling to meet its contractual obligations, or it may experience financial, operational or other difficulties.

\section{Currency}

Fluctuations in an agreement's denominated currency compared to the financing company's home currency may result in financial losses. There is also a potential upside to this if the currency appreciates in value. 


\subsection{Resource Company Risks}

Resource companies also have multiple exposures. Only exposures related to the relationship between the financing and resource companies are raised here, in particular those related to operation and the environment. Wider exploration, third party and more general business issues, such as taxation, access to finance and competitive access to resources, and the obtaining/renewal of permits and licences, are not discussed.

\section{Operations}

Operations are subject to multiple factors that lead to exposure, including: weather related events; unusual and unexpected geology formations; seismic activity, rock bursts, cave-ins and pit-wall failures; environmental hazards and discharge of toxic chemicals; explosions and other conditions involved in the drilling, blasting and removal of material; equipment failure; and poor industrial relations.

These types of factors could result in ceasing production, damage to property, injury or loss of life, environmental damage, work stoppages, delays in production, increased production costs and possible legal liability. The likelihood of many of these factors occurring can be reduced through the adoption of safe and proper work, management, design and planning practices (Sandstorm Gold, 2013). Adverse weather conditions and seismic activity are location dependent.

\section{Environment}

Resource companies are responsible for complying with any environmental legislation, and such legislation appears to be increasing with time. Fines, compensation to others, withdrawal of permits and enforcement actions may apply for non-compliance. Environmental hazards may carry over from previous uses of the site when legislation may not have been as strict. This can result in costs for corrective or remedial actions (Sandstorm Gold, 2013).

\section{EXAMPLE CALCULATIONS}

Calculations involving financial risks in gold mining are given, comparing streaming agreements and royalty-based agreements (profit-based and revenue-based), using the following data and assumptions:

- The life of the mine is assumed to be 10 years, with accounting done annually.

- Streaming agreement, and revenue-based royalty agreement - initial loan of \$35M.

- Profit-based royalty agreement - initial loan of $\$ 10 \mathrm{M}$.

- Streaming agreement: The financing company has the right to purchase $15 \%$ of the mine's production.

- Royalty agreement (revenue-based): The royalty rate is $7 \%$ of revenue.

- Royalty agreement (profit-based): The royalty rate is $20 \%$ of profit.

- Average annual production is 50,000 ounces/year.

- Average gold market price is $\$ 1400 /$ ounce.

- Cost of production is $\$ 1200 /$ ounce. This cost includes allowances for depreciation and amortisation.

- The mining company does not use any of its own capital to fund the project, except in the case of the profit-based royalty agreement, where it has to provide the difference of $\$ 25 \mathrm{M}$ (that is, $\$ 35 \mathrm{M}$ minus $\$ 10 \mathrm{M}$ ).

- Gold is purchased by the financing company at a fixed price of $\$ 400 /$ ounce (as per the streaming agreement).

- Gold is sold annually by both the financing company and the mining company at the market price. 
- Costs for the production of the gold are only recognised at the end of each accounting period, (when the gold is sold and delivered to the financing company).

- There are no deductions made from the revenue or profit.

In terms of the calculations: the time unit (in line with most streaming agreements) is a year; and the production and the market price of gold are random variables, but uncorrelated. An interest rate of $7 \%$ is used. Discount rates used for deterministic analyses might be higher than this, however for probabilistic PW calculations, the uncertainty is already incorporated in the cash flows, and hence the interest rate requires no additional loading for this uncertainty.

For each random variable, optimistic (a), most likely (b) and pessimistic (c) values are estimated as is done in PERT. This then gives, expected value or mean $=(a+4 b+c) / 6$, and variance $=[(c-a) / 6]^{2}$. (See for example, Carmichael, 2006; Carmichael and Balatbat, 2008). Here, optimistic and pessimistic values in the following are assumed to be in the range of \pm $15-25 \%$ of the most likely values, which are also assumed to be the average values. Other assumptions could be used, such as different plus and minus percentages, and different percentages for each variable, or expert estimates. The assumptions give:

- Annual production, E[Prod $]=50000$ ounces; $\operatorname{Var}[\operatorname{Prod}]=(3333 \text { ounces })^{2}$

- Market price of gold, $\mathrm{E}[\mathrm{MPr}]=\$ 1400 /$ ounce; $\operatorname{Var}[\mathrm{MPr}]=(\$ 67 / \text { ounce })^{2}$

- Production cost of gold, $\mathrm{E}[\mathrm{Pcost}]=\$ 1200 /$ ounce; $\operatorname{Var}[\mathrm{Pcost}]=(\$ 60 / \text { ounce })^{2}$

- Purchase price of gold, $\mathrm{E}[\mathrm{Pur}]=\$ 400 /$ ounce.

The relevant cash flows are given in Tables 1 and 2.

Correlations also need to be estimated, though independence and complete correlation might be appropriate assumptions in many cases. Suggestions for obtaining estimates for correlation coefficients may be found for example in Hillier (1969), Kim and Elsaid (1988), Kim et al. (1999), and Johar et al. (2010), Carmichael and Balatbat (2010), Carmichael (2014). In the calculations that follow, where correlation is assumed, generally a correlation coefficient of 1 is used in the calculation of covariances. However, other correlation coefficients can be used, and do not change the degree of difficulty of the calculations.

Also in the calculations that follow, a normal distribution is assumed for present worth, on the basis that the present worth is obtained from additive yearly components. This view is supported by Hillier (1963) and Tung (1992) among others. However, users are free to adopt whatever distribution they think is appropriate. The nature of the calculations does not change.

Expressions for expected values and variances for functions can be found, for example, in Benjamin and Cornell (1970), Ang and Tang (1975) and Carmichael (2014).

\subsection{Streaming Agreement - Financing Company}

Let the stream rate be $\alpha$, which here equals $15 \%$.

\section{Cash outflows}

Initial loan provided to the mining company (deterministic), $\mathrm{Y}_{01}$

$$
\mathrm{E}\left[\mathrm{Y}_{01}\right]=\$ 35.00 \mathrm{M}
$$

Ore purchases as per the streaming agreement, $Y_{i 2}=$ Pur $\alpha$ Prod, $i=1,2, \ldots, 10$.

$\mathrm{E}\left[\mathrm{Y}_{\mathrm{i} 2}\right]=$ Pur $\alpha \mathrm{E}[$ Prod $]=\$ 3.00 \mathrm{M}$

$$
\operatorname{Var}\left[Y_{\mathrm{i} 2}\right]=(\operatorname{Pur} \alpha)^{2} \operatorname{Var}[\operatorname{Prod}]=(\$ 0.20 \mathrm{M})^{2}
$$


Cash inflows

Revenue from ore sales (delivered under the streaming agreement), $\mathrm{Y}_{\mathrm{i} 3}=\operatorname{MPr} \alpha \operatorname{Prod}, \mathrm{i}=1,2$,

$\ldots, 10$. For Mpr and Prod independent,

$$
\begin{gathered}
\mathrm{E}\left[\mathrm{Y}_{\mathrm{i} 3}\right]=\mathrm{E}[\mathrm{MPr}] \alpha \mathrm{E}[\operatorname{Prod}]=\$ 10.50 \mathrm{M} \\
\operatorname{Var}\left[\mathrm{Y}_{\mathrm{i} 3}\right]=\alpha^{2}\left\{\mathrm{E}^{2}[\mathrm{Mpr}] \operatorname{Var}[\operatorname{Prod}]+\mathrm{E}^{2}[\operatorname{Prod}] \operatorname{Var}[\mathrm{Mpr}]+\operatorname{Var}[\mathrm{Mpr}] \operatorname{Var}[\operatorname{Prod}]\right\} \\
=(\$ 0.86 \mathrm{M})^{2}
\end{gathered}
$$

Combining correlated $\mathrm{Y}_{\mathrm{i} 2}$ and $\mathrm{Y}_{\mathrm{i} 3}$ over $\mathrm{i}=1,2, \ldots, 10$,

$$
\begin{aligned}
& \mathrm{E}\left[\mathrm{X}_{\mathrm{i}}\right]=-\mathrm{E}\left[\mathrm{Y}_{\mathrm{i} 2}\right]+\mathrm{E}\left[\mathrm{Y}_{\mathrm{i} 3}\right]=\$ 7.50 \mathrm{M} \\
& \operatorname{Var}\left[\mathrm{X}_{\mathrm{i}}\right]=\operatorname{Var}\left[\mathrm{Y}_{\mathrm{i} 2}\right]+\operatorname{Var}\left[\mathrm{Y}_{\mathrm{i} 3}\right]-2 \mathrm{Cov}\left[\mathrm{Y}_{\mathrm{i} 2}, \mathrm{Y}_{\mathrm{i} 3}\right]=(\$ 0.66 \mathrm{M})^{2}
\end{aligned}
$$

Present worth, using Equations (6) to (8),

$$
\begin{aligned}
& \mathrm{E}[\mathrm{PW}]=\$ 17.67 \mathrm{M} \\
& \operatorname{Var}[\mathrm{PW}]=(\$ 1.50 \mathrm{M})^{2}
\end{aligned}
$$

A normal distribution may be fitted to PW. The probability of the financing company losing money, $\mathrm{P}[\mathrm{PW}<0]$, is close to zero.

\subsection{Streaming Agreement - Mining Company}

A similar set of equations can be worked for the mining company.

\section{Cash inflows}

Initial loan provided to the mining company (deterministic), $\mathrm{Y}_{01}$

$$
\mathrm{E}\left[\mathrm{Y}_{01}\right]=\$ 35.00 \mathrm{M}
$$

Stream sales as per the streaming agreement, $Y_{i 2}=$ Pur $\alpha$ Prod, $i=1,2, \ldots, 10$.

$\mathrm{E}\left[\mathrm{Y}_{\mathrm{i} 2}\right]=$ Pur $\alpha \mathrm{E}[$ Prod $]=\$ 3.00 \mathrm{M}$

$$
\operatorname{Var}\left[Y_{i 2}\right]=(\operatorname{Pur} \alpha)^{2} \operatorname{Var}[\operatorname{Prod}]=(\$ 0.20 \mathrm{M})^{2}
$$

Ore sales at market price to other buyers, $Y_{i 3}=\operatorname{MPr}(1-\alpha) \operatorname{Prod}, i=1,2, \ldots, 10$.

$$
\begin{gathered}
E\left[Y_{i 3}\right]=E[M P r](1-\alpha) E[\operatorname{Prod}]=\$ 59.50 M \\
\operatorname{Var}\left[Y_{i 3}\right]=(1-\alpha)^{2}\left\{E^{2}[M p r] \operatorname{Var}[\operatorname{Prod}]+E^{2}[\operatorname{Prod}] \operatorname{Var}[M p r]+\operatorname{Var}[M p r] \operatorname{Var}[\operatorname{Prod}]\right\} \\
=(\$ 4.88 M)^{2}
\end{gathered}
$$

Cash outflows

Production costs, $\mathrm{Y}_{\mathrm{i} 4}=$ PcostProd, $\mathrm{i}=1.2, \ldots, 10$.

$$
\begin{gathered}
\mathrm{E}\left[\mathrm{Y}_{\mathrm{i} 4}\right]=\operatorname{Cov}[\text { Pcost, Prod }]+\mathrm{E}[\text { Pcost }] \mathrm{E}[\text { Prod }]=\$ 60.20 \mathrm{M} \\
\operatorname{Var}\left[\mathrm{Y}_{\mathrm{i} 4}\right] \approx \mathrm{E}^{2}[\text { Pcost }] \operatorname{Var}[\text { Prod }]+\mathrm{E}^{2}[\text { Prod }] \operatorname{Var}[\text { Pcost }]+ \\
2 \mathrm{E}[\text { Pcost }] \mathrm{E}[\text { Prod }] \operatorname{Cov}[\text { Pcost,Prod }]=(\$ 7.00 \mathrm{M})^{2}
\end{gathered}
$$

Combining correlated $\mathrm{Y}_{\mathrm{i} 2}, \mathrm{Y}_{\mathrm{i} 3}$ and $\mathrm{Y}_{\mathrm{i} 4}$ over $\mathrm{i}=1,2, \ldots, 10$,

$$
\begin{gathered}
\mathrm{E}\left[\mathrm{X}_{\mathrm{i}}\right]=\mathrm{E}\left[\mathrm{Y}_{\mathrm{i} 2}\right]+\mathrm{E}\left[\mathrm{Y}_{\mathrm{i} 3}\right]-\mathrm{E}\left[\mathrm{Y}_{\mathrm{i} 4}\right]=\$ 2.30 \mathrm{M} \\
\operatorname{Var}\left[\mathrm{X}_{\mathrm{i}}\right]=\operatorname{Var}\left[\mathrm{Y}_{\mathrm{i} 2}\right]+\operatorname{Var}\left[\mathrm{Y}_{\mathrm{i} 3}\right]+\operatorname{Var}\left[\mathrm{Y}_{\mathrm{i} 4}\right] \\
\quad+2\left\{\operatorname{Cov}\left[\mathrm{Y}_{\mathrm{i} 2}, \mathrm{Y}_{\mathrm{i} 3}\right]-\operatorname{Cov}\left[\mathrm{Y}_{\mathrm{i} 2}, \mathrm{Y}_{\mathrm{i} 4}\right]-\operatorname{Cov}\left[\mathrm{Y}_{\mathrm{i} 3}, \mathrm{Y}_{\mathrm{i} 4}\right]\right\} \\
=(\$ 1.92 \mathrm{M})^{2}
\end{gathered}
$$

Present worth, using Equations (6) to (8),

$$
\begin{aligned}
& \mathrm{E}[\mathrm{PW}]=\$ 51.15 \mathrm{M} \\
& \operatorname{Var}[\mathrm{PW}]=(\$ 4.35 \mathrm{M})^{2}
\end{aligned}
$$


A normal distribution may be fitted to PW. The probability of the mining company losing money, $\mathrm{P}[\mathrm{PW}<0]$, is close to zero.

\subsection{Revenue-based Royalty Agreement - Financing Company}

Let the royalty rate be $\beta$, which here equals $7 \%$ of revenue.

Cash outflows

Initial loan provided to the mining company (deterministic), $\mathrm{Y}_{01}$

$\mathrm{E}\left[\mathrm{Y}_{01}\right]=\$ 35.00 \mathrm{M}$

Cash inflows

Royalty payments (as per the royalty agreement), $\mathrm{Y}_{\mathrm{i} 2}=\operatorname{MPr} \beta \operatorname{Prod} . \mathrm{i}=1,2, \ldots, 10$. For Mpr and Prod independent,

$$
\begin{gathered}
\mathrm{E}\left[\mathrm{Y}_{\mathrm{i} 2}\right]=\mathrm{E}[\mathrm{MPr}] \beta \mathrm{E}[\mathrm{Prod}]=\$ 4.90 \mathrm{M} \\
\begin{array}{c}
\operatorname{Var}\left[\mathrm{Y}_{\mathrm{i} 2}\right]=\beta^{2}\left\{\mathrm{E}^{2}[\mathrm{Mpr}] \operatorname{Var}[\operatorname{Prod}]+\mathrm{E}^{2}[\operatorname{Prod}] \operatorname{Var}[\mathrm{Mpr}]+\operatorname{Var}[\mathrm{Mpr}] \operatorname{Var}[\operatorname{Prod}]\right\} \\
=(\$ 0.40 \mathrm{M})^{2}
\end{array}
\end{gathered}
$$

Present worth, using Equations (6) to (8),

$$
\begin{aligned}
& \mathrm{E}[\mathrm{PW}]=-\$ 0.58 \mathrm{M} \\
& \operatorname{Var}[\mathrm{PW}]=(\$ 0.91 \mathrm{M})^{2}
\end{aligned}
$$

A normal distribution may be fitted to PW. The probability of the financing company losing money, $\mathrm{P}[\mathrm{PW}<0]$, is approximately 0.73 . Clearly the royalty rate of $7 \%$ would need to be increased from the finance company's viewpoint.

\subsection{Revenue-based Royalty Agreement - Mining Company}

Cash inflows

Initial loan provided to the mining company (deterministic), $\mathrm{Y}_{01}$

$$
\mathrm{E}\left[\mathrm{Y}_{01}\right]=\$ 35.00 \mathrm{M}
$$

Ore sales at market price, $\mathrm{Y}_{\mathrm{i} 2}=$ MPrProd, $\mathrm{i}=1,2, \ldots, 10$.

$$
\begin{gathered}
\mathrm{E}\left[\mathrm{Y}_{\mathrm{i} 2}\right]=\mathrm{E}[\mathrm{MPr}] \mathrm{E}[\mathrm{Prod}]=\$ 70.00 \mathrm{M} \\
\operatorname{Var}\left[\mathrm{Y}_{\mathrm{i} 2}\right]=\mathrm{E}^{2}[\mathrm{Mpr}] \operatorname{Var}[\operatorname{Prod}]+\mathrm{E}^{2}[\operatorname{Prod}] \operatorname{Var}[\mathrm{Mpr}]+\operatorname{Var}[\mathrm{Mpr}] \operatorname{Var}[\operatorname{Prod}] \\
=(\$ 5.74 \mathrm{M})^{2}
\end{gathered}
$$

Cash outflows

Royalty payments (as per the royalty agreement), $\mathrm{Y}_{\mathrm{i} 3}=\operatorname{MPr} \beta \operatorname{Prod} . \mathrm{i}=1,2, \ldots, 10$. For Mpr and Prod independent,

$$
\begin{gathered}
\mathrm{E}\left[\mathrm{Y}_{\mathrm{i} 3}\right]=\mathrm{E}[\mathrm{MPr}] \beta \mathrm{E}[\operatorname{Prod}]=\$ 4.90 \mathrm{M} \\
\begin{aligned}
\operatorname{Var}\left[\mathrm{Y}_{\mathrm{i} 3}\right]=\beta^{2}\left\{\mathrm{E}^{2}[\mathrm{Mpr}] \operatorname{Var}[\operatorname{Prod}]+\mathrm{E}^{2}[\operatorname{Prod}] \operatorname{Var}[\mathrm{Mpr}]+\operatorname{Var}[\mathrm{Mpr}] \operatorname{Var}[\operatorname{Prod}]\right\} \\
=(\$ 0.40 \mathrm{M})^{2}
\end{aligned}
\end{gathered}
$$

Production costs, $\mathrm{Y}_{\mathrm{i} 4}=$ PcostProd, $\mathrm{i}=1.2, \ldots, 10$.

$\mathrm{E}\left[\mathrm{Y}_{\mathrm{i} 4}\right]=\operatorname{Cov}[$ Pcost, Prod $]+\mathrm{E}[\mathrm{Pcost}] \mathrm{E}[$ Prod $]=\$ 60.20 \mathrm{M}$

$\operatorname{Var}\left[\mathrm{Y}_{\mathrm{i} 4}\right] \approx \mathrm{E}^{2}[\mathrm{Pcost}] \operatorname{Var}[\operatorname{Prod}]+\mathrm{E}^{2}[\operatorname{Prod}] \operatorname{Var}[\operatorname{Pcost}]+$ $2 \mathrm{E}[$ Pcost $] \mathrm{E}[$ Prod $] \mathrm{Cov}[$ Pcost, Prod $]=(\$ 7.00 \mathrm{M})^{2}$ 
Combining correlated $\mathrm{Y}_{\mathrm{i} 2}, \mathrm{Y}_{\mathrm{i} 3}$ and $\mathrm{Y}_{\mathrm{i} 4}$ over $\mathrm{i}=1,2, \ldots, 10$,

$$
\begin{aligned}
& \mathrm{E}\left[\mathrm{X}_{\mathrm{i}}\right]=\mathrm{E}\left[\mathrm{Y}_{\mathrm{i} 2}\right]-\mathrm{E}\left[\mathrm{Y}_{\mathrm{i} 3}\right]-\mathrm{E}\left[\mathrm{Y}_{\mathrm{i} 4}\right]=\$ 4.90 \mathrm{M} \\
& \operatorname{Var}\left[\mathrm{X}_{\mathrm{i}}\right]=\operatorname{Var}\left[\mathrm{Y}_{\mathrm{i} 2}\right]+\operatorname{Var}\left[\mathrm{Y}_{\mathrm{i} 3}\right]+\operatorname{Var}\left[\mathrm{Y}_{\mathrm{i} 4}\right] \\
& \quad+2\left\{-\operatorname{Cov}\left[\mathrm{Y}_{\mathrm{i} 2}, \mathrm{Y}_{\mathrm{i} 3}\right]-\operatorname{Cov}\left[\mathrm{Y}_{\mathrm{i} 2}, \mathrm{Y}_{\mathrm{i} 4}\right]+\operatorname{Cov}\left[\mathrm{Y}_{\mathrm{i} 3}, \mathrm{Y}_{\mathrm{i} 4}\right]\right\} \\
& =(\$ 1.66 \mathrm{M})^{2}
\end{aligned}
$$

Present worth, using Equations (6) to (8),

$$
\begin{aligned}
& \mathrm{E}[\mathrm{PW}]=\$ 69.42 \mathrm{M} \\
& \operatorname{Var}[\mathrm{PW}]=(\$ 3.76 \mathrm{M})^{2}
\end{aligned}
$$

A normal distribution may be fitted to PW. The probability of the mining company losing money, $\mathrm{P}[\mathrm{PW}<0]$, is close to zero.

\subsection{Profit-based Royalty Agreement - Financing Company}

Profit-based royalties generally have a lower initial payment made to the mining company by the financing company. This is done in order to lower the risk to the financing company. Let the royalty rate be $\lambda$, which here equals $20 \%$ of profit.

\section{Cash outflows}

Initial loan provided to the mining company (deterministic), $\mathrm{Y}_{01}$

$$
\mathrm{E}\left[\mathrm{Y}_{01}\right]=\$ 10.00 \mathrm{M}
$$

\section{Cash inflows}

Royalty payments (as per the royalty agreement), (MPr - Pcost) $\lambda$ Prod.

Let $Y_{i 2}=\operatorname{MPr} \lambda \operatorname{Prod}$, and $Y_{i 3}=\operatorname{Pcost} \lambda \operatorname{Prod}, \mathrm{i}=1,2, \ldots, 10$. For Mpr and Prod independent,

$$
\begin{gathered}
\mathrm{E}\left[\mathrm{Y}_{\mathrm{i} 2}\right]=\mathrm{E}[\mathrm{MPr}] \lambda \mathrm{E}[\mathrm{Prod}]=\$ 14.00 \mathrm{M} \\
\operatorname{Var}\left[\mathrm{Y}_{\mathrm{i} 2}\right]=\lambda^{2}\left\{\mathrm{E}^{2}[\mathrm{Mpr}] \operatorname{Var}[\operatorname{Prod}]+\mathrm{E}^{2}[\operatorname{Prod}] \operatorname{Var}[\mathrm{Mpr}]+\operatorname{Var}[\mathrm{Mpr}] \operatorname{Var}[\operatorname{Prod}]\right\} \\
=(\$ 1.15 \mathrm{M})^{2}
\end{gathered}
$$

For Pcost and Prod correlated,

$$
\begin{array}{r}
\mathrm{E}\left[\mathrm{Y}_{\mathrm{i} 3}\right]=\lambda \operatorname{Cov}[\text { Pcost, Prod }]+\mathrm{E}[\text { Pcost }] \lambda \mathrm{E}[\operatorname{Prod}]=\$ 12.04 \mathrm{M} \\
\operatorname{Var}\left[\mathrm{Y}_{\mathrm{i} 3}\right] \approx \lambda^{2}\left\{\mathrm{E}^{2}[\text { Pcost }] \operatorname{Var}[\text { Prod }]+\mathrm{E}^{2}[\text { Prod }] \operatorname{Var}[\text { Pcost }]+\right. \\
2 \mathrm{E}[\text { Pcost }] \mathrm{E}[\operatorname{Prod}] \operatorname{Cov}[\text { Pcost }, \operatorname{Prod}]\}=(\$ 1.40 \mathrm{M})^{2}
\end{array}
$$

Combining correlated $\mathrm{Y}_{\mathrm{i} 2}$ and $\mathrm{Y}_{\mathrm{i} 3}$ over $\mathrm{i}=1,2, \ldots, 10$,

$$
\begin{aligned}
& \mathrm{E}\left[\mathrm{X}_{\mathrm{i}}\right]=\mathrm{E}\left[\mathrm{Y}_{\mathrm{i} 2}\right]-\mathrm{E}\left[\mathrm{Y}_{\mathrm{i} 3}\right]=\$ 1.96 \mathrm{M} \\
& \operatorname{Var}\left[\mathrm{X}_{\mathrm{i}}\right]=\operatorname{Var}\left[\mathrm{Y}_{\mathrm{i} 2}\right]+\operatorname{Var}\left[\mathrm{Y}_{\mathrm{i} 3}\right]-2 \operatorname{Cov}\left[\mathrm{Y}_{\mathrm{i} 2}, \mathrm{Y}_{\mathrm{i} 3}\right]=(\$ 0.25 \mathrm{M})^{2}
\end{aligned}
$$

Present worth, using Equations (6) to (8),

$$
\begin{aligned}
& \mathrm{E}[\mathrm{PW}]=\$ 3.77 \mathrm{M} \\
& \operatorname{Var}[\mathrm{PW}]=(\$ 0.57 \mathrm{M})^{2}
\end{aligned}
$$

A normal distribution may be fitted to PW. The probability of the mining company losing money, $\mathrm{P}[\mathrm{PW}<0]$, is close to zero.

\subsection{Profit-based Royalty Agreement - Mining Company}

Cash inflows

Initial loan provided to the mining company (deterministic), $\mathrm{Y}_{01}$ 
$\mathrm{E}\left[\mathrm{Y}_{01}\right]=\$ 10.00 \mathrm{M}$

Ore sales at market price, $\mathrm{Y}_{\mathrm{i} 2}=\operatorname{MPrProd}, \mathrm{i}=1,2, \ldots, 10$.

$$
\begin{gathered}
\mathrm{E}\left[\mathrm{Y}_{\mathrm{i} 2}\right]=\mathrm{E}[\mathrm{MPr}] \mathrm{E}[\operatorname{Prod}]=\$ 70.00 \mathrm{M} \\
\begin{aligned}
\operatorname{Var}\left[\mathrm{Y}_{\mathrm{i} 2}\right]=\mathrm{E}^{2}[\mathrm{Mpr}] \operatorname{Var}[\operatorname{Prod}]+\mathrm{E}^{2}[\operatorname{Prod}] \operatorname{Var}[\mathrm{Mpr}]+\operatorname{Var}[\mathrm{Mpr}] \operatorname{Var}[\operatorname{Prod}] \\
=(\$ 5.74 \mathrm{M})^{2}
\end{aligned}
\end{gathered}
$$

\section{Cash outflows}

Balance of initial capital (deterministic), $\mathrm{Y}_{02}$

$$
\mathrm{E}\left[\mathrm{Y}_{02}\right]=\$ 25.00 \mathrm{M}
$$

Royalty payments (as per the royalty agreement), (MPr - Pcost) $\lambda$ Prod.

Let $\mathrm{Y}_{\mathrm{i} 3}=\operatorname{MPr} \lambda \operatorname{Prod}$, and $\mathrm{Y}_{\mathrm{i} 4}=\operatorname{Pcost} \lambda \operatorname{Prod}, \mathrm{i}=1,2, \ldots, 10$. For Mpr and Prod independent,

$\mathrm{E}\left[\mathrm{Y}_{\mathrm{i} 3}\right]=\mathrm{E}[\mathrm{MPr}] \lambda \mathrm{E}[\mathrm{Prod}]=\$ 14.00 \mathrm{M}$

$$
\begin{gathered}
\operatorname{Var}\left[\mathrm{Y}_{\mathrm{i} 3}\right]=\lambda^{2}\left\{\mathrm{E}^{2}[\mathrm{Mpr}] \operatorname{Var}[\operatorname{Prod}]+\mathrm{E}^{2}[\operatorname{Prod}] \operatorname{Var}[\mathrm{Mpr}]+\operatorname{Var}[\mathrm{Mpr}] \operatorname{Var}[\operatorname{Prod}]\right\} \\
=(\$ 0.67 \mathrm{M})^{2}
\end{gathered}
$$

For Pcost and Prod correlated,

$$
\begin{gathered}
\mathrm{E}\left[\mathrm{Y}_{\mathrm{i} 4}\right]=\lambda \operatorname{Cov}[\text { Pcost, Prod }]+\mathrm{E}[\mathrm{Pcost}] \lambda \mathrm{E}[\text { Prod }]=\$ 12.04 \mathrm{M} \\
\operatorname{Var}\left[\mathrm{Y}_{\mathrm{i} 4}\right] \approx \lambda^{2}\left\{\mathrm{E}^{2}[\text { Pcost }] \operatorname{Var}[\operatorname{Prod}]+\mathrm{E}^{2}[\text { Prod }] \operatorname{Var}[\text { Pcost }]+\right. \\
2 \mathrm{E}[\text { Pcost }] \mathrm{E}[\operatorname{Prod}] \operatorname{Cov}[\text { Pcost }, \text { Prod }]\}=(\$ 1.40 \mathrm{M})^{2}
\end{gathered}
$$

Production costs, $\mathrm{Y}_{\mathrm{i} 5}=$ PcostProd, $\mathrm{i}=1.2, \ldots, 10$.

$$
\begin{gathered}
E\left[Y_{i 5}\right]=\operatorname{Cov}[\text { Pcost, Prod }]+E[\text { Pcost }] \mathrm{E}[\text { Prod }]=\$ 60.20 \mathrm{M} \\
\operatorname{Var}\left[\mathrm{Y}_{\mathrm{i} 5}\right] \approx \mathrm{E}^{2}[\text { Pcost }] \operatorname{Var}[\text { Prod }]+\mathrm{E}^{2}[\text { Prod }] \operatorname{Var}[\text { Pcost }]+ \\
2 \mathrm{E}[\text { Pcost }] \mathrm{E}[\text { Prod }] \operatorname{Cov}[\text { Pcost }, \text { Prod }]=(\$ 7.00 \mathrm{M})^{2}
\end{gathered}
$$

Additional capital required at start, $\mathrm{Y}_{06}=-35+10=-\$ 25 \mathrm{M}$

Combining correlated $\mathrm{Y}_{\mathrm{i} 2}, \mathrm{Y}_{\mathrm{i} 3}, \mathrm{Y}_{\mathrm{i} 4}$ and $\mathrm{Y}_{\mathrm{i} 5}$ over $\mathrm{i}=1,2, \ldots, 10$, and letting

$$
\begin{aligned}
& X_{i}=Y_{i 2}-Y_{i 3}+Y_{i 4}-Y_{i 5}=\sum_{j=2}^{5} a_{j} Y_{i j} \\
& E\left[X_{i}\right]=\sum_{j=2}^{5} a_{j} E\left[Y_{i j}\right]=\$ 7.84 M \\
& \operatorname{Var}\left[X_{i}\right]=\sum_{j=2}^{5} a_{j}^{2} \operatorname{Var}\left[Y_{i j}\right]+2 \sum_{j=2 k=3}^{4} \sum_{j}^{5} a_{k} \operatorname{Cov}\left[Y_{i j}, Y_{i k}\right]=(\$ 0.53 M)^{2}
\end{aligned}
$$

Present worth, using Equations (6) to (8),

$$
\begin{aligned}
& \mathrm{E}[\mathrm{PW}]=\$ 40.06 \mathrm{M} \\
& \operatorname{Var}[\mathrm{PW}]=(\$ 1.20 \mathrm{M})^{2}
\end{aligned}
$$

A normal distribution may be fitted to PW. The probability of the mining company losing money, $\mathrm{P}[\mathrm{PW}<0]$, is close to zero.

\subsection{Sensitivity}

Sensitivity-style analyses can be carried out on the analysis variables of interest rate, streaming/royalty rate, purchase price and so on, in order to establish how the probability of losing money changes with changes in the underlying variables. The analysis remains unchanged except for the value of the variables for which sensitivity is being gauged.

A complete risk analysis would involve such sensitivity-style analyses. They are not performed here because the process repeats, but with different numerical values, the above calculations. 


\subsection{Risk}

Risk is a combination of likelihood and magnitude. The above analyses demonstrate how to calculate likelihoods or probabilities associated with losing/gaining from a project. Depending on the risk attitude of the streaming/royalty company and the mining company, so they might regard the different combinations of likelihood and loss/gain magnitudes as, for example, high, medium or low risk. Establishment of actual risk depends on the risk attitudes of the parties, and general statements on risk cannot be made.

An examination of $\mathrm{P}[\mathrm{PW}<0]$, together with associated losses/gains, for each of the agreement parties for each of the financing agreements will indicate the degree of risk involved in each case. Although in the numerical examples above, many of these probabilities are small, this will not be the case for different agreement values. It is then up to the financing and mining companies to establish what are acceptable probability levels.

An examination of E[PW] for each of the agreement parties for each of the financing agreements will indicate likely returns in each case. It is then up to the financing and mining companies to establish what are acceptable returns. It is noted that, all else being equal, higher uncertainty leads to higher returns. Against this, people tend to dislike higher uncertainty.

As well, there are other matters influencing the choice of agreement type, such as levels of capital and cash flows, and consideration of these would need to be incorporated into any complete analysis.

\section{HEDGING VIA OPTIONS}

Options may be used as a hedging tool to cover against large fluctuations in the underlying prices and production. The above analysis requires little extra work should there be an option included in the financing agreement. An option is a right but not an obligation to do something in the future. It gets its value from the future uncertainty. Example options are:

- The option to change from one financing agreement (streaming or royalty) to a different agreement (streaming or royalty) at, or up to, year T. That is, there is an option to convert the agreement from one form to another.

- The option to modify the initial agreement, for example by changing the $\alpha, \beta$ or $\lambda$ percentages in the financing agreement, at or up to time $\mathrm{T}$.

$\mathrm{T}$ may be fixed or variable. The option right may be given to either the financing company or the mining company, as agreed by the parties.

Consider an option to convert from agreement $\mathrm{A}$ to an agreement $\mathrm{B}$ at time $\mathrm{T}$. To evaluate the option, the cash flows associated with A and B, at and beyond $\mathrm{T}$, are subtracted and then discounted to time 0 , to give the expected value of the present worth, PW, of these combined (by differencing) cash flows.

Fitting a normal distribution to present worth, then the value of the option is given by Equation (9) (Carmichael, 2014).

For the party without the option right, an amount of money might be included in the original agreement between the parties as compensation for the other party having the option right. The amount of money included should relate to the option value calculated using Equation (9).

\section{CONCLUSION}

It was shown that by using a second order moment analysis, an understanding and assessment of risk associated with stream and royalty financing can be readily obtained. It overcomes all the deficiencies associated with conventional deterministic analysis incorporating sensitivity. The analysis tells the degree to which an investment is viable, that is, it is able to differentiate grades of separation from some viability benchmark, and is able 
to establish the likelihoods of occurrence. It is also able to establish true investment risk, and is less vulnerable to assumptions on the analysis variables by properly accounting for potential variability or uncertainty in the analysis variables. It readily permits the incorporation of options, as hedging, for example to change an agreement.

A case example study demonstrated the evaluation of returns and risk, and comparisons made between different financing alternatives.

The financial analysis was supplemented with discussion on non-financial issues, to give a more complete risk analysis.

\section{REFERENCES}

Andersen, J. and Honeyman J. (2013), Stream Financing: a Primer, Strikeman Elliott LLP, accessed 12 December 2013, http://www.lexology.com/library/detail.aspx?g=14c951a761ef-45d4-b305-bbebbb6be47c

Ang, A. H-S. and Tang, W. H. (1975), Probability Concepts in Engineering Planning and Design, Vol. I, Wiley, New York.

Benjamin, J. R. and Cornell, C. A. (1970), Probability, Statistics, and Decision for Civil Engineers, McGraw-Hill, New York.

Breen, S. (2013), Alternative Financing Methods for Mineral Projects, Gowling Lafleur Henderson LLP, accessed 19 January 2014, http://www.lexology.com/library/detail.aspx?g=13864efe-5bee-431c-a690b8ce1005a74c

Callinan (n.d.), Our Business: Royalties, Callinan Royalties Corporation, accessed 22 January 2014, http://www.callinan.com/s/royalties.asp

Careaga, A. (2012), Mineral Royalty Stream Financing, Wealthmark LLC, accessed 12 December 2013, http://www.slideshare.net/besget/mineral-royaltystreamfinancing

Carmichael, D. G. (2004), Project Management Framework, A. A. Balkema, Rotterdam, Swets \& Zeitlinger B. V., Lisse.

Carmichael, D. G. (2006), Project Planning, and Control, Taylor and Francis, London.

Carmichael, D. G. (2011), An Alternative Approach to Capital Investment Appraisal, The Engineering Economist, Vol. 56, No. 2, pp. 1-17, 2011.

Carmichael, D. G. (2013), Problem Solving for Engineers, CRC Press, Taylor and Francis, London.

Carmichael, D.G. (2014), Infrastructure Investment, CRC Press, Taylor and Francis, London.

Carmichael, D. G. and Balatbat, M. C. A. (2008), Probabilistic DCF Analysis, and Capital Budgeting and Investment - A Survey, The Engineering Economist, Vol. 53, No. 1, pp 84-102.

Carmichael, D. G. and Balatbat, M. C. A. (2010), A Review and Study of Project Investment Cash Flow Correlations, International Journal of Project Planning and Finance, Vol. 1, No. 1, pp. 1-21.

Carmichael, D. G., Hersh, A. M. and Parasu, P. (2011), Real Options Estimate Using Probabilistic Present Worth Analysis, The Engineering Economist, Vol. 56, No. 4, pp. 295-320.

Franco-Nevada (n.d.), Types of Royalties and Other Agreements, Franco-Nevada, accessed 22 January 2014, http://www.franco-nevada.com/assets/types-royalties

Hillier, F. S. (1963), The Derivation of Probabilistic Information for the Evaluation of Risky Investments, Management Science, vol. 9, no. 3, pp. 443-457.

Hillier, F. S. (1969), The Evaluation of Risky Interrelated Investments, North-Holland Pub. Co., Amsterdam.

Johar, K., Carmichael, D. G. and Balatbat, M. C. A. (2010), A Study of Correlation Aspects in Probabilistic NPV Analysis, The Engineering Economist, Vol. 55, No. 2, pp. 181-199. 
Kalt, R. (2010), The Accretive Use of Metal Stream Financing: The Mine Financing Strategy that Reduces Dilution and Accelerates Production, Gold Royalties Corporation, accessed 18 December 2013,

http://www.goldroyalties.ca/metals_streams_royalties_VPPs_reserve_purchase_agreeme nts.php

Kim, S. H. and Elsaid, H. H. (1988), Estimation of Periodic Standard Deviations under the Pert and Derivation of Probabilistic Information, Journal of Business Finance \& Accounting, Vol. 15, No. 4, pp. 557-571.

Kim, S. H., Hussein, H. E. and Kim, D. J. (1999), Derivation of an Intertemporal Correlation Coefficient Model Based on Cash Flow Components and Probabilistic Evaluation of a Project's NPV, The Engineering Economist, Vol. 44, No. 3, pp. 276-294.

Lewis, D., Seetulsingh, A., Drysdale, A., Sealey, P., Renshaw, T., Pay, J., Simmons, D. and Pistilli, M. (2013), Alternative Financing for Natural Resource Companies: Bringing Future Cashflows On-stream, Clifford Chance, accessed 18 December 2013, http://www.cliffordchance.com/publicationviews/publications/2013/02/alternative_finan cingfornaturalresourc.html

Otto, J. Andrews, C., Cawood, F. Dogget, M. Guj, P., Stermole, F., Stermole, J. and Tilton, J. (2006), Mining Royalties: A Global Study of Their Impact on Investors, Government and Civil Society, Mining Royalties, The World Bank, accessed 25 March 2014, http://www.scribd.com/doc/93203917/Mining-Royalties-A-Global-Study-of-theirImpact-on-Investors-Government-and-Civil-Society

Sandstorm Gold (2013), 2013 Third Quarter Report, Sandstorm Gold, accessed 13 February 2014, http://www.sandstormgold.com/_resources/financials/2013/SSL-Q3-2013.pdf

Silver Wheaton (n.d.), Company Profile, Silver Wheaton, accessed 30 April 2014, http://www.silverwheaton.com/Company/Profile/default.aspx

Taplin, R. and Deutscher, P. (2013), Financing in Difficult Times: Metal Streaming Transactions, McCarthy Tétrault LLP, accessed 18 January 2014, http://www.lexology.com/library/detail.aspx?g=3c79f422-c64b-4fb6-a67babac47e4d070

Tung, Y. K. (1992), Probability Distribution for Benefit/Cost Ratio and Net Benefit, Journal of Water Resources Planning and Management, Vol. 118, No. 2, pp. 133-150. 